\title{
Mitigation strategies in examiners' reports of Mphil theses
}

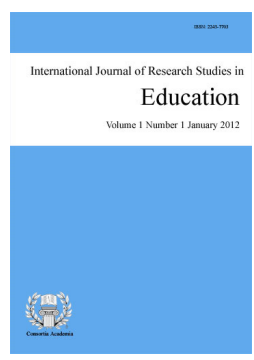

\section{Abstract}

The use of outright negative comments may demoralize the spirit of the candidate and even destroy interpersonal relationships. For the purposes of maintaining social relationships, therefore, negative or critical comments are, sometimes, mitigated in the thesis examiners' reports (TERs). Drawing on Hyland's (2000) taxonomy of strategies, the study investigated the strategies that examiners employ to mitigate critical comments in 100 theses examiners' reports written by examiners on MPhil theses. The analysis revealed that critical/negative comments made by examiners in TERs were mitigated through, mainly, the praise and criticism pairs and hedging devices. Also, examiners, sparingly, employed questions, and personal responsibility to mitigate critical comments in TERS. The study has implications for postgraduate pedagogy that teachers and students should situate their couching and writing skills to maintain interpersonal relationships and to avoid potential rejection by interlocutors respectively.

Keywords: examiners' reports, critical comments, Hyland's taxonomy, mitigation strategies, Mphil theses 


\section{Mitigation strategies in examiners' reports of Mphil theses}

\section{Introduction}

The use of outright negative comments as written feedback in postgraduate training may demoralize the spirit of the candidate and even destroy interpersonal relationships. To maintain social relationships, negative or critical comments are, sometimes, mitigated in the thesis examiners' reports (TERs). Hyland and Hyland (2001) identified some reasons why critical comments were mostly mitigated. The first of the reasons was that examiners tried not to devastate the candidates by criticizing all issues identified in the work. A second reason was that examiners would like to represent themselves as readers rather than individuals who are the custodians of all knowledge in the area of investigation. A third reason was the need not to appropriate or usurp students' text. Students are to own their texts (Brannon \& Knoblauch, 1982). Knoblauch and Brannon (1984, p. 118) have explained that writing can be "stolen" from a writer by the examiner's comments. They suggest that if students follow directive feedback too closely, they may develop neither their cognitive skills nor their writing abilities, but merely rewrite texts to reflect their teachers' concerns. Softening criticisms will help mitigate over-directive interferences in the students' writings.

An additional reason given for the mitigation of critical comments is to save the face or 'public self-image' of candidates. Goffman (1966) discusses face as the positive self-image that a person holds when interacting with other people. Since face is neither inherent in nor permanent, once a positive face is offered, that individual feels the need to maintain that image. Brown and Levinson (1978, p. 66) develop the concept of face further by indicating that face is "something that is emotionally invested, and can be lost, maintained, or enhanced, and must be constantly attended to in interaction". Obeng (1996, p. 521) found that "Akans (one of the major ethnolinguistic groups in Ghana) use proverbs in the management of face, mitigating to reduce the offensive intent of 'difficult' utterance, and showing a speaker's humility or acknowledgment of the addressee's sensibility". In TERs, the face of the examiner, both positive and negative, is threatened, but to maintain that face of being approved by others while avoiding being distracted by others, the evaluative acts used in the TERs are, sometimes, mitigated. The last reason for mitigating critical comments is that examiners often consider this as a way of maintaining or developing good relationships with the candidates in that social relations or interpersonal relations can be destroyed if the only comment received from the other party is just direct criticisms, destroying the candidate's sense of worth and killing self-confidence. Recognising thus, the importance of TERS, the present study aims to investigate the mitigation strategies that are employed by Ghanaian academics in a public university. It is expected that findings in the study will broaden the horizon of scholarly on TERS, and help teachers and students to appropriate their discourses well.

\section{Literature Review}

Several studies have investigated the language of evaluation, focusing on expert writings such as research articles (Hyland, 2005), book reviews (e.g. Alcaraz-Ariza, 2010; Giannoni, 2002), and review reports (e.g. Kosonen, 2014), graduate writing like maters' thesis (e.g. Edusie, 2015; Musa, 2014), and student feedback (e.g. Hyland \& Hyland, 2001; Razali \& Jupri, 2014).

First, some studies have investigated use of evaluative language in research articles, appealing to the use of mitigation strategies. Hyland (2005) analyzed a corpus of 240 research articles from ten leading journals in eight disciplines. The analysis showed that a model of how writers use linguistic resources to reflect the practices of their disciplinary communities and to represent themselves, their positions, and their readers was proposed, including hedges. Besides, Gillaerts and Van de Velde (2010) analysed the use of hedges, boosters, and attitude markers in research article abstracts in applied linguistics. The results indicated that the distribution of hedges, boosters, and attitude markers in abstracts differed from their distribution in research articles.

16 Consortia Academia Publishing (A partner of Network of Professional Researchers and Educators) 
Research article is not the only expert writing that has been studied for the use of evaluative language but also book reviews. Hyland (2000) investigates the use of praise and criticism by writers in eight disciplines. His study revealed that praise was used more in addressing general aspects of the reviewed book and particular reference to content issues. Besides, Giannoni (2002), also, focused on expert writings (EWs) by identifying a number of rhetorical strategies associated with expressions of praise and criticism in English software reviews. The study revealed that though mostly downtowners, seven of the rhetorical strategies served to make negative evaluation more poignant. Hyland (2004) pointed to the use of praise in the opening sections of the book review as an effective strategy to mitigate the criticisms and its application in the closing sections in order to protect the book author's positive face. Moreover, Mackiewicz (2007) also examined the extent to which positive evaluation (compliments) and negative evaluation (criticism) in BRs from three academic journals were carried out. The findings of the study demonstrated that reviewers complimented more than they criticized, but mitigated critical comments. Also, Alcaraz-Ariza (2010) aimed to identify the evaluative speech acts in a corpus of 30 English-written medical BRs published in The British Medical Journal in the period, 2000-2009. The study found that various strategies were used not only to soften criticism but also to maintain social harmony and solidarity with the reviewees. In addition, Itakura and Tsui (2011) employed Brown and Levinson's (1987) model to analyze 20 English and 20 Japanese BRs to find out how criticism was managed. Their analysis revealed that English BRs encompassed more praise to establish solidarity and rapport while Japanese BRs included apology and self-denigration.

Combining different genre types, Jalali (2017) examined a particular structural group of lexical bundles encoding stance expression in three corpora of research articles, doctoral dissertations, and master theses in applied linguistics. The analyses showed that the bundles contained stance expressions of hedging, marking attitude, stressing emphasis, attributing, and making epistemic meanings. Salager-Meyer (2001) also analyzed the linguistic expressions used to convey disagreement in the four main genres of health communication, 50 each, published in mainstream English-written medical periodicals. The results indicated that editorialists expressed their criticisms in a direct, authoritarian, highly personal and frequently ironic, condescending and/or sarcastic tone. Authors of review articles also tend to voice their disagreement in a categorical and assured way but without emotionally involving themselves. By contrast, research articles writers, convey their critical comments in an apparently humble and unimposing tone. Finally, the situational context of case reports had scarcity of criticism in that particular genre.

However, these are not the only genres that have received attention on the use of language of evaluation. The language of thesis examiners' reports (TERs) has also been studied. For instance, Kosonen (2014) investigated the evaluative language of preliminary examiners' statements in the WrELFA corpus, focusing on how examiners gave recommendations, looking at the general trends in modal verb usage and self-mention. The study revealed that the evaluative process of pre-examination in Social Sciences and Humanities was much closer to a dialogue, a negotiation of ideas and viewpoints. In Natural Sciences, however, it was more about procedure, data, and results rather than the actors who were doing the interpreting.

With respect to graduate writing, Musa (2014) investigated the discourse functions of hedges in English and Chemistry Masters' theses in the University of Cape Coast. Employing a mixed method approach, the study revealed that hedging in Chemistry was higher than English, but, on the whole, hedges were used to performed three pragmatic functions: make claims accompanied by some degree of uncertainty; prevent any future criticism capable of damaging image, and gain reader acceptability by presenting facts as tentative. Edusie (2015) investigated hedging strategies among Advanced L2 Users of English in three universities- Kwame Nkrumah University of Science and Technology, University of Education, Winneba, and University of Cape Coast. Some findings of Edusie's study included the epistemic/non-epistemic use of hedging devices, with many pragmatic functions and complexity levels.

In addition to expert and graduate writing, evaluation has been studied on student feedback for their use of mitigation strategies. Hyland and Hyland (2001) offered a detailed textual analysis of the written feedback (WF) 
given by two teachers to ESL students in a proficiency course. They considered this feedback in terms of its functions as praise, criticism, and suggestions. The analysis of the study indicated that Praise was the most frequently employed function in the feedback of these two teachers, but this was often used to soften criticisms and suggestions rather than simply responding to good work. Many of the criticisms and suggestions were also mitigated by the use of hedging devices, question forms, and personal attribution. Razali and Jupri (2014) investigated the effects of teacher written feedback on undergraduates' writing in an English L2 classroom at Universiti Malaysia Perlis, exploring the use of suggestion, criticism, and praise. The study revealed that all types of teacher written feedback (WF) encouraged student revisions, but criticism resulted in more successful revisions as it was more specific. Furthermore, Gborsong, Awiah, and Appartaim (2018) investigate the nature and location of teachers' written feedback comment on sixty-two (62) students' project essays selected from four Colleges of Education in Ghana, to, specifically, ascertain the syntactic/linguistic form of comments written by the teachers. They identified that hedges which occurred in evaluations of content were made using suggestion/request comments. Teachers' comments were also mitigated.

The above studies indicate that evaluative language, with specific reference to mitigation, have been studied extensively in expert writings and student writings (graduate writing and student feedback). The language of thesis examiners' reports has also been studied. It has been established so far that not many studies have investigated mitigation strategies in thesis examiners' reports in Ghana, in general, and University of Cape Coast, in particular, which runs many postgraduate programmes, and examine such theses. As members of the academic community, examiners would like to maintain relationship with the audience of these reports; thus, the need to examine the strategies examiners employ to mitigate critical comments.

\subsection{Interpersonal metafunction}

The study draws on the interpersonal mode of systemic functional linguistics. Halliday (1978, p. 112) explicates that "the interpersonal component represents the speaker's meaning potential as an intruder", which allows speakers to intrude into the context of situation, both expressing their own attitudes and judgements, and seeking to influence the attitudes and behaviour of others. For Martin and White (2005), interpersonal resources are concerned with negotiating social relations: how people are interacting, including the feelings they try to share. Attention is on the use of language to interact with people, establish and maintain social connections, give and request information, and convey viewpoints, attitudes as well as beliefs about the world. The interpersonal metafunction suggests that when people are involved in a communicative event, they are not only transmitting and sharing meaning; rather they negotiate, establish and sustain relationships (Martin \& White, 2005; Thompson, 2014).

\subsection{The Taxonomy of Strategies of Mitigation}

Hyland (2000) identifies mitigating strategies such as praise-criticism (PC) pairs, hedging, personal responsibilities, and questions. First, Hyland (2000) identifies Praise-Criticism (PC) pair, which include: Praise-Criticism (PC) pair, criticism-praise (CP), Praise-Criticism-Suggestion (PCS) pair, and Criticism-Suggestion (CS) pair. Hyland (2000, p. 55) describes PC pair as a situation where "Praise is subordinated to criticism, but their adjacency serves to create a more balanced comment, slightly softening the negativity of the evaluation." Besides, CP pair is a strategy where praise is added to criticism. With PS pair, praise is offered, followed by a suggestion. In addition, PCS pair as a mitigation strategy starts with a praise comment that expresses a liking, a negative comment that shows disliking, and a suggestion to help improve upon the thesis or its components. Lastly, CS pair has a negative comment presented which is followed by a suggestion.

The second mitigation strategy is hedging. Boncea (2014) defines hedging as the main strategy used to facilitate turn-taking, show politeness and mitigate face-threats. Boncea (2014) elaborates further the importance of hedging that: first, hedging has aroused interest and curiosity because it is a means of conveying vagueness

18 Consortia Academia Publishing (A partner of Network of Professional Researchers and Educators) 
purposely. Hedging is used by speakers and writers to convey certainty or doubt towards a statement and to show the degree of confidence they assign to their claim. Second, by using hedges, writers allow their readers to evaluate the truth value of the assertion. Third, Hedging reflects a high degree of efficiency in social interaction by demonstrating the ability to express degrees of certainty and mastering rhetorical strategies required in conversational circumstances. Hedges are instantiated through the use of modal verbs, imprecise quantifiers, lexical softeners, 'Usuality’ expressions and hypothetical clause.

A third mitigation strategy identified is the use of question forms. Hyland and Hyland (2001) explain that questions are a means of highlighting knowledge limitations, and can be used to weaken the force of a statement by making it relative to a writer's state of knowledge. While they, generally, seek to engage and elicit a response from the reader, questions also express the writer's ignorance or doubt and, therefore, can mitigate the imposition of a suggestion or a criticism. The last strategy is Personal responsibility which is employed to introduce a speaker's personal opinion and interpretation of some available information, and to diminish the strength propositions (Hyland, 2000; Hyland \& Hyland, 2001).

These strategies were adopted in analysing the data to ascertain how critical evaluative comments are mitigated in theses examiners' reports in a different socio-cultural context, although as in several countries worldwide, English language is used as the lingua franca in academic communication, in general, and publishing, in particular.

\section{Methodology}

Research Design - I employed the qualitative research design because I aimed to describe, explain and interpret the mitigation strategies that were employed in the examiners' reports on MPhil theses submitted to the School of Graduate Studies, University of Cape Coast. Hundred (100) reports in 2006-2016 on MPhil theses were purposely sampled from the departments of English and History (from Faculty Arts), and Population and Health, and Hospitality and Tourism Management (from Faculty of Social Sciences) which constituted the data. In selecting the data, I was interested in reports with three or more sentences on a particular evaluative criterion at a time, so that I could ascertain the use of mitigation strategies at play. Examiners' reports obtained from these departments were photocopied. By adopting the qualitative content analysis, I was enabled to closely read the reports so as to identify and understand the mitigation strategies employed in the reports.

Data Analysis Procedure - I draw on Hyland's (2000) taxonomy of strategies earlier espoused to identify the mitigation strategies. For the coding of the data, I numbered the reports from 1-25 for each discipline. For instance, the first English report was tagged ENG I; second ENG 2 up to the last item, ENG 25. HOT represented Hospitality and Tourism Management; HIS for History, and POH for Population and Health. Coding the data enabled me to easily identify the various distinctive forms of mitigation strategies in the data and analysed them. The analysis was organized according to the themes that emerged. These identified themes were further broken down into smaller emerging patterns. For example, a coding system, "PC" representing the sub-theme of "Praise/Criticism" pairs under the model of Hyland was used.

\section{Analysis and Discussion}

Four mitigation strategies identified in the data are discussed here. Each strategy is discussed with evidence from the data and its interpretation in relation to the literature, and in terms of prominence.

\subsection{Praise-Criticism (PC) pairs}

This pair for mitigating critical evaluative comments was realised in five different forms: praise-Criticism (PC) pairs, criticism-praise (CP) pairs, praise-criticism-suggestion (PCP) pairs, praise-suggestion (PS) pairs, and criticism-suggestion (CS) pairs. 
The first mitigation strategy presented for analysis is Praise-Criticism (PC) pair. Here, praise fronts the criticism:

The candidate has done a very interesting and insightful study but the quality of presentation is rather poor. (HIS 1)

Indeed, the candidate has a section entitled 'Findings', which has a semblance of discussion, but it is scanty and too pedestrian for my liking. (ENG 4)

The presentation is systematic, logical and detailed. However, the main body of the writing is plagued by a number of infelicitous items of expression unworthy of this level of writing. (POH 18)

A lot of materials have been collected for this work but unfortunately the trend of reasoning does not flow including a lot of repetition- and text-book stuff.

(HOT 4)

For example, in Extract 1 above, although the examiner is concerned about the presentation, the praise comment is strategically added to reduce the full illocutionary force of the negative statement (Hyland, 2000). Alcaraz-Ariza (2010), Gborsong et al. (2018), and Mackiewicz (2007) also found that the mitigation of critical comments in their study was meant to maintain face at each point in time, and not only to soften criticism, ultimately maintaining social harmony and solidarity with the reviewees. In Extract 3, the examiner stresses that the language used in the work does not accord with the level of the candidate. The use of the figurative expression, 'plagued', metaphorically denotes the poor state of the use of language in the writing of the entire work. Also, the use of evaluative adjectives, 'infelicitous' and 'unworthy' speaks to the defect in the thesis. To reduce the potency of the negative comment, a praise comment is introduced earlier in the statement, evoking Crick's (1990, p. 49) observation:

... if you have something critical to say about a piece of scientific work, it is better to say it firmly but nicely and to preface it with praise of any good aspect of it. I only wish I had always stuck to this useful rule.

Crick (1990), indeed, suggests that negative comments in scientific writing or academic writings should be asserted strongly but politely; this can be achieved by skirting a positive comment around a negative comment. In the view of Salager-Meyer (2001) critically attacking others' work in contemporary science is a very sensitive issue.

The Praise-Criticism (PC) strategy was found in such sections of the thesis as the Literature Review, Methodology, and Presentation:

Sufficient empirical data were presented to support the claims; yet, the researcher could not adequately identify the gaps in the literature reviewed, to serve as the basis for the study. (POH 4)

The candidate showed good knowledge of the subject through literature review and is also commended for the justification of the study; however, the reporting of data and discussions are not thorough enough. (HOT 24)

The candidate had all the information on the methodology, but some aspects were poorly executed e.g. the data collection/fieldwork. (ENG 8)

The study is interesting and readable but there is repetition of information throughout the work. (HIS 4)

As found in Extracts 5-8, whereas an examiner combines praise and criticism (PC) to address the inadequacy in 
the LR, another uses the same mitigation strategy, PC, in the methodology, with the negative comment specifically on the data collection. So, in Extract 7, two positive (praise) comments which touch on the subject matter of the study and justification precede the negative (criticism) which is on the data and discussion, an attempt to soften the criticism on the discussion, where the substance of the whole study is, where new information found is supported by data (Holliday, 2007; Lynch, 2014).

Apart from the structural form - PCs — identified above, Hyland and Hyland (2001) also identified other pairs that help soften criticism. These include criticism-praise pairs, praise-criticism-suggestion pairs, praise-suggestion pairs, and criticism-suggestion pairs. In the present study, the analysis of the data revealed that these identified pairs by Hyland and Hyland (2001) are deployed in the data; these are briefly discussed below.

First, CP strategy has praise at the end of the construction while criticism is fronted in the information. The common communicative function performed by this pair, here, is that the full weight of the criticism is reduced. Examples of the CP pairs in the data:

Although the second chapter was not necessarily historical in its approach, chapters 3 and 4 are the major contributions to Ghana's history and the candidate should be praised for that. (HIS 15)

Though I have raised a few queries, the presentation is good and commendable. (ENG 15)

The reporting of the data and discussion are not thorough enough. These errors notwithstanding, the candidate demonstrated good understanding on the study topic.

(POH 19)

Though the study design employed for the study was not the best and has to be visited, the qualitative approach employed for the study is appropriate and the data collected were relevant. (HOT 19)

In Extract 11, we observe that the candidate did not have an exhaustive discussion; this notwithstanding, the candidate is praised for demonstrating a proven understanding of the topic investigated. Here, the critical comment will not be pleasantly received, but the added praise comment which expresses satisfaction of an output by the study attenuates the full impact of the negative comment. The examiners have employed many linguistic resources to achieve the effect of mitigating the critical comments like the concessive clause which has 'although', 'though' and 'notwithstanding'; use of inherent negative words and expressions like, 'not necessarily', 'not the best', 'few queries', and 'not thorough enough', and a positive word expressed in adjectives, 'appropriate' and 'relevant'; nominals like, 'major contributions, 'commendable', 'good understanding'; and verb, 'praised. These linguistic resources, both negative and positive, blend to mitigate the critical comment; thus, maintaining solidarity with readers, candidate, and supervisor (Halliday, 1978; Martin \& White, 2005).

Another strategy is the Praise-Suggestion (PS) pair, where praise is offered, followed by a suggestion:

The level of data analysis is acceptable but could have been better. For example, the between years (2003 and 2008) trends in the data could have been compared and differences explained. (POH 23)

The problem guiding the study is well formulated but can be improved.

The work I must admit is well researched, well written and supervised and one of the few good theses I have examined in recent past. However, first sentence of the third paragraph on p. 61 needs rephrasing. (ENG 13) 
In general, the candidate has paid much attention to the use of language and used the appropriate phraseology required for the topic selected. A few instances of misuse of capital letters should be corrected. (HIS 20)

In Extract 13, the examiner applauds the candidate for the analysis done through the use of the adjective, 'acceptable', but continues that there is more room for improvement. An example is cited further to buttress the assertion that something can be done to improve the current state of the work. The use of the PS pair does not leave the candidate devastated like a full-blown critical comment would have done. Hyland and Hyland (2001) note that such a comment both directly contributes to learning and creates the interpersonal conditions in which learning may occur. Again, they observed in their study that suggestions tended to be pedagogically more useful.

A further approach identified to moderate the effect of critical/negative comments was the Praise-Criticism-Suggestion pair. This mitigation strategy starts with a praise comment that expresses a liking, a negative comment that shows disliking, and a suggestion to help improve upon the thesis or its components. This style of mitigation in the data is illustrated below:

The specific objectives of the study are consistent with the topic investigated. However, there is disconnection between the research topic and the main objective. This needs to be addressed. (ENG 2)

The mixed method employed for the study is appropriate and the data collected were relevant. However, the researcher seems to confuse the interview schedule with in-depth interview. This aspect has to be revisited. (ENG 7)

The objectives were specific and achieved at the end of the study. However, even though the researcher stated at page 16, line 3 hypothesis, it could not be identified in the text. I suspect, it was omitted and that it should be inserted to make the study complete. (HOT 20)

The conceptual framework of $X$ that explains behaviour and health services utilization was appropriate but its adoption was poorly constructed and explained. The subcomponent of the original model should be well explained and points of departure in this new study vividly outline(sic) and justified. (POH 18)

As seen above, Extract 18 indicates that the mixed method including the relevant data collected for the study used is suitable. On the other hand, the succeeding remark shows a discrepancy in the work over the terms used for the instrument in the collection of the data, using the verbal phrase 'seems to confuse'. The suggestion is that this aspect has to be redrafted. Again, whereas praise is showered on the candidate for the choice of an appropriate framework, its adoption is 'poorly constructed' and not 'explained', using an adverb added to verbal phrases (Extract 20). This, the examiner suggests 'should be well explained, and 'points of departure in this new study vividly outlined(sic) and justified.' Hyland and Hyland (2001) caution teachers (here, examiners) to often consider their choice of comments to accomplish informational, pedagogic, and interpersonal goals simultaneously; else, a negative comment may have a detrimental effect on writer confidence and motivation; thus, the use of this method to attenuate critical comment in the data.

The penultimate major mitigation strategy identified in the data was the Criticism-Suggestion pair. Here, a negative comment is presented, followed by a suggestion. The full force of the criticism is assuaged by the second part of the duo. Some cases of CS pair are presented below:

Aspects relating to conclusions and recommendations were not adequately treated and have to be improved. (HOT 17) 
The methodology was poorly presented. The candidate should re-work the chapter systematically and convincingly. (POH 1)

The findings of the study are scanty. A comprehensive list of all findings should be presented in the summary and conclusion chapter. (POH 22)

The tables used in the work are too many. Some have to be emerged to reduce the number (31). (ENG 23)

In Extract 22 shows a criticism, which is that the methodology 'was poorly presented', requiring a rewriting of the chapter. Similarly, in Extract 23, the examiner indicates that the tables in the thesis are 'too many' a negative appraisal, and that the number of the tables be merged.

In addition to the strategies identified in the data, the analysis of the present study revealed another strategy: Suggestion-Criticism-Praise. This strategy was not among those noted by Hyland and Hyland (2001), signalling the importance of context in the use of language (Eggins, 2004; Halliday \& Matthiessen, 2004; Martin \& White, 2005). For Salager-Meyer (2001), the linguistic strategies used to convey academic conflict are not only discipline-specific, but also epoch- and language/culture-bound. Below are some illustrations of SCP:

The significance of the study has to be improved and expanded. The practical value of the research work is missing, even though the problem statement which emphasizes on poor performance of travel intermediaries is good. (HOT 12)

The candidate should highlight the outstanding deduction from the figures. If we examine the figures in pg (sic).120, for instance, which particular variety...stands out for $X, Y$ and $Z$. However, this observation does not detract from the fact that this is an impressive analysis of the data. There is clear evidence that the candidate has a good deal of control of the tool of analysis. (ENG 6)

The problem guiding the study can be improved. It is too long. But both the main and specific objectives of the study are consistent with the topic investigated. (POH 4)

Kindly effect all the corrections indicated in the main thesis. The major problem you have here is that many in-text citations are not in the reference list. However, generally, the candidate spent time to work on the report and the language as well as the overall quality is quite commendable. (POH 5)

Extract 25 contains the suggestion that there could be improvement on the significance of the study, indicating that the work is not in its acceptable form yet. The criticism which also adds to this imperfection observed in the suggestion indicates that the significance of the study is absent. The obvious negative illocutionary force of these comments is assuaged by a praise at the end of the extract, commending the candidate for his/her ability to articulate the problem of the study well. In addition, in Extract 26, the candidate is asked to show the significant deductions that can be made from the figures, and a question is posed to the candidate as to the kind of variety used for $\mathrm{X}, \mathrm{Y}$ and $\mathrm{Z}$. Contrary to the identified defects, the analysis is found to be impressive enough - a praise which is to soften the negative comments given earlier on. Perhaps, since SCP did not occur in Hyland and Hyland (2001), the strategy can be said to be non-native and culture- specific. It looks a bit illogical, but, like all the other mitigation strategies, negotiating and maintaining interpersonal relationships matters a lot. Again, since the comments found in the reports contribute to learning, directly and indirectly, recipients of the reports ought to be motivated and encouraged to be more confident.

In sum, it was found that the mitigated criticism occurs with a praise which is skirted around criticism and suggestion, yielding praise-criticism, criticism-praise, praise-suggestion, praise-criticism-suggestion, criticism-suggestion, and suggestion-criticism-praise pairs. According to Hyland and Hyland (2001), criticisms 
that are linked to suggestions help expand what may be seen as a blunt criticism into a proposal for improvement. These strategies, with their attendant linguistic resources such as adverb, adjective, verb, and noun, reflect a positive relationship between the reader (student/teacher), and the writer/author (examiner) (Hyland, 2000; Martin \& White, 2005).

\subsection{Hedges}

Hyland (1998) explains hedges as any linguistic means used to indicate a lack of complete commitment to the truth value of an accompanying proposition or the desire not to express that commitment categorically. Hedges can be seen as the expression of the attitude of a speaker or writer making an attempt to protect him/herself from potential rejection from an interlocutor (Boncea, 2014). Thus, the principal function of hedges considered in the present study is neither the suggestion of probability nor its other functions such as their epistemic and affective meaning (Boncea, 2014; Hyland, 1998; Musa, 2014), but the attenuation of a critical comment. Hedges manifest in forms such as modal verbs, lexical forms, imprecise quantifiers, and usuality devices (Hyland \& Hyland, 2001). The analysis of the present data reveals the use of some of these hedging devices as a means to mitigate the full effect of critical comments given by examiners.

First, the most widely found modal used to soften critical comments in the data were 'could', 'may', and 'would'. Samples are as follows:

The level of data analysis could have been improved with graphical methods. (POH 11)

The under-listed references in the reference section could not be traced in the text. (HIS 2)

He may consider sectionalizing the study to make easy reference. (ENG 19)

It would also be helpful to address the question of balancing normative ethics and applied ethics with real situation on the ground in the hotel industry. (HOT 14)

The modals in Extracts 29-32 above make uncertain the critical comments. For example, in Extract 30, there is a suggestion that the under-listed reference is missing from the reference, through the use of modal auxiliary 'could'. The writer is not emphatic as he chooses to hedge his claim of the missing references. In Extract 32, the comment is made uncertain by the use of 'would', not mandating the candidate but offering a suggestion to the candidate. Ngula (2017) categorized 'could' and 'would' weak and medium epistemic claims. In the view of Hyland (1995), the use of hedges by the examiners helps contribute to the development of a healthy writer-reader relationship, addressing the need for deference and cooperation in gaining reader ratification of claims.

Added to the modal verbs as hedging devices were the imprecise quantifiers which, according to Boncea (2014), are used when the exactness of an item cannot be determined or vouched for; thereby, creating fuzziness (Lakoff, 1972). Displayed below are instances of hedging devices in the data:

It lacks any analytical discourse and adds little of value to knowledge. (POH 7)

There is very little discussion on the recommendations made by the candidate (ENG 13)

There are some weaknesses in the chronology in sections of the narrative. (HIS 5)

The work is replete with some erroneous concepts. (HOT 13)

In Extract 34, the examiner hedges by indicating that there is a level of discussion in the recommendation, although this is seen as 'very little'. Extract 35 also indicates that there are weaknesses in the sequence of events in the narrative, though it is not in its totality, but 'some'. Clearly, examiners use these imprecise quantifiers to avoid committing themselves fully; thereby, helping to reduce the full effect of negative comments and to 
negotiate or maintain interactions with the readers.

Another hedging device is derived from what Hyland and Hyland (2001) view as 'usuality' expressions. They include linguistic choices such as 'often' and 'sometimes', which express 'habituality' and 'typicalness'. Some samples are provided below:

The candidate writes well but sometimes, he uses complicated expressions that make the meaning of what he wants to say unclear. (HOT 20)

Another major problem was that the candidate often depended on his imagination and current practices. (HIS 18)

At times, the writer falls into the problem of literally translated Twi concepts into English. (HIS 1)

He, however, at times, does not press home certain points in his analysis.

(POH 17)

According to Extract 37, the candidate writes well, but occasionally, uses expressions that do not make clear meanings, and these are done, sometimes, when candidate literally translates Twi concepts into English (Extract 39). These are problems, negative in nature and elicits the examiner's dissatisfaction with the wording of the candidate. However, the full force of this negative comment is mitigated with the usuality devices. Also, 'at times' as found in Extract 39, is used in Extract 40 for a similar effect. The effect of the combination of the usuality device and aberration is that the wrong is only commented sparingly.

In addition, hedges are instantiated through the use of lexical softeners, which the present study reveals abound in the use of adverbs and verbs more than adjectives:

The researcher seems to confuse the interview schedule with in-depth-interview.

(HOT 13)

The research problem is somewhat stated. (ENG 4)

The assumptions emanating from the review of related literature are quite relevant and interesting. (HOT 12)

The candidate indicated fair knowledge of the subject through literature review.

(POH 11)

While Extract 41 deploys a lexical verb 'seems', Extracts 42 and 43 employ adverbs, represented as 'somewhat' and 'quite' respectively. The last of the extracts here, 44, uses an adjective, 'fair'. Falahati (2006) asserts that these lexical words enable writers to show either their extent of certainty or doubt towards their statements, and to show the amount of confidence they put in their claim. For instance, by asserting that knowledge displayed by the candidate is 'fair' (Extract 44), the examiner weakens the assertion and prevents him/herself from making a categorical statement that can damage the social interactions. Here, it can be said that the use of hedges allows examiners to leave some room for readers to think, creating that interaction between a writer and an audience in that prose (Bakhtin, 1981; Falahati, 2006). As seen in Extracts 41-44, some hedging devices accompanied positive statements. The examiner intends to remark that there are some inadequacies but to remove the effect that critical comments will have on the audience, hedged expressions are rather used. The examiner observes that it is 'quite relevant and interesting', considering the assumptions that are deduced from the Literature Review. In a way, this expression is the best one expected, but to remark that the assumptions are not the best or are poor may impede social interaction; hence, the use of the hedged device, 'quite', in the sentence.

In addition, hedges occurred in negative ECs, as shown in the data below:

The background information appears jumpy and not logical. (HIS 21) 
The knowledge displayed of the relevant literature is barely adequate. (ENG 10)

The suggestions made by the candidate for further research are rather slight. (POH 23)

For example, as observed in Extract 46, the barely adequate nature of the LR shows a disliking for the level of knowledge shown by the candidate. Also, in Extract 47 the examiner considers the suggestions made by the candidate as 'slight' (meaning) insignificant, anticipating that something substantial could have been presented. This is an inadequacy, which is negative but it is shielded in a hedging device, 'rather'. This indeterminacy adds an amount of fuzziness or uncertainty to the comment expressed (Boncea, 2014; Lakoff, 1972), and confirming Hyland's view that hedges "imply that a statement is based on plausible reasoning rather than certain knowledge" (Hyland, 2005, p.179).

The last kind of the hedging devices found in the data was the hypothetical forms. Hypothetical clause or the if-clause shows tentativeness in making an assertion (Boncea, 2014). Here, the examiner is unwilling to describe the state of affairs as certain but as an assumption; thereby, leaving some room for the student, to save his/her face. In a sense, the full force of the remark is not felt since the hypothetical statement is to be considered as a postulation. Examples of this hedging device are presented in the following extracts:

If these are done then the soundness of the discussion, which is lingering behind the cloud of those concerns will appear well and become poignant. (HIS 20)

If the candidate states that the government is still working on the legal framework for the licensing of tour guides, then it means that it is work in progress and not necessary a delay in the concluding it. (HOT 4)

If they are expressed this way, the discussion will become clearer than what the candidate has done. (POH 19)

If we do that, then we will have just one goal stated as purpose (1) which will be fine.

(ENG 15)

The examiner remarks that action must be taken to ensure the soundness of the discussion (Extract 48). As it stands, the discussion is defective, but the examiner hedges through the hypothetical form to reduce the harshness of the critical comment. The conditional-hypothetical clause expresses tentativeness, allowing the student to do the rest of the speculation. It is a proposition that does not dictate to the student; thereby, allowing the student to maintain his/her image.

At this stage, it is interesting to point out that some comments tended to contain more than a hedging device. That is, it is possible to identify multiple hedging devices in a single evaluative comment:

On the whole, the thesis appears quite well written and structured. (HOT 2)

One would have expected the candidate to provide some empirical evidence to justify the need for the study. (ENG 13)

The description of the study area was rather brief and also could have been appreciated better in location terms if the study area map was provided. (HOT 23)

A graphical pattern for Ghana similar to Figure 1 would have been useful, even though table 1 seemly appears to do so. $\quad$ (POH 20)

For example, whereas Extract 52 deploys 'appears' and 'quite', Extract 53 has 'would' and 'some'. Others include 'rather' and 'could' (Extract 54) as well as 'would', 'seemly' and 'appears' (Extract 55). Boncea (2014) calls this 'constellation of hedges' whereas Hyland and Hyland (2001) refer to them as 'clusters'. In the view of Hyland and Hyland (2001), these 'clusters' of hedges reinforce one another, helping to achieve the overall effect

26 Consortia Academia Publishing (A partner of Network of Professional Researchers and Educators) 
of removing the sting further from the critical comment.

Furthermore, the hedges were 'smeared' on the entire thesis and realized in many different sections of the thesis:

The piece is fairly well written. (ENG 5)

The literature is fairly current. (HOT 3)

The research questions and objectives seem to be broader than the actual study carried out. (HOT 7)

The scope of the study is rather limiting. (POH 6)

The comments above (56-59) refer to some aspects of the theses that have been differently hedged, including the thesis in totality (Extract 56), Literature Review (Extract 57), research questions (Extract 58), and scope of the study (Extract 59). Almost all the extracts seem to be cast in praise or positive comments in addition to the hedging devices. The examiner comments that the issues are not well presented. To weaken the effect that a critical comment might have caused, a praise with a hedged device is rather preferred.

Other parts of the thesis received some of these hedging devices, as contained in the following extracts:

Referencing is quite satisfactory. ( $\mathrm{POH} 11)$

The recommendations were generally good. (ENG 2)

The candidate's language is quite good and clear. (HIS 12)

The student has attempted to weave a well-connected nice narrative.... the narrative has been created but it is waiting to shine. (HIS 15)

We see other sections such as referencing (Extract 60) and recommendations in (Extract 61) with hedged devices. Again, the linguistic devices used for hedging ranged from the use of mostly adverbs such as 'fairly', 'quite', and 'generally' (in Extracts 60, 61, and 62 respectively) to verbs such as 'seem', and 'attempted' in Extracts 58 and 63. The use of hedging devices in different aspects of theses in the present study confirms the assertion of Falahati (2006) that hedging expressions can also be used in describing methods and results by examiners, discussing findings, and drawing conclusions from the evidence. This realization contradicts Hyland and Hyland (2001), who found that hedges were found with content, probably, because teachers base their feedback on how best assigned essays can be improved.

The above discussion has shown that hedging is an effective strategy used in thesis examiners' reports (TERs). As found in the data, there were varying hedging devices such as modal verbs, imprecise quantifiers, usuality devices, lexical forms, and hypothetical forms. In some instances, clusters of hedges were used for reinforcement. Also, the hedges were found in all sections of the thesis, and were cast in both negative and positive comments.

\subsection{Question Forms}

A third mitigation strategy identified in the data was the use of question forms. Find examples of interrogative forms in the data below:

If Africans were practicing slavery and slave trade before European intrusion into Africa, how could you challenge as 'erroneous' 'contentions that Africans willing offered themselves to be enslaved or were sold by their own brothers'? (pp. 110,121). (ENG 18) 
Why a new proposed model for travel motivation and satisfaction? Is this the beginning of a new thesis with the same null hypothesis? (HOT 4)

What does the author mean? Nyankumasi or Nyankomase? (HIS 17)

Why is analysis done at the ecological zone level instead of at the regional level? (POH 19)

The analysis also reveals that most of the questions were cast in WH-forms. Quirk and Greenbaum (1973) declare that such question forms mostly demand a reply which supplies an item of information: that is, what they refer to as interrogative words (Q-words). It is probably so in the analysis in that the interrogative forms with the Wh or Q-words are used when the examiners seek to engage and elicit a response from the reader more as well as to express their ignorance or doubt and, therefore, mitigate the imposition of a suggestion or a criticism (Hyland \& Hyland, 2001). So, in Extract 64, the assertion made by the candidate with regard to Africans practicing slavery before the arrival of the Europeans is challenged by the examiner. The examiner could have directly indicated that candidate's standpoint in relation to practice of slavery by Africans was wrong, but by using the questioning form, the examiner wants the candidate to reflect upon the issue. Also, in Extract 67, the examiner attempts to find out why the analysis was carried out at 'ecological zone level' and not at the 'regional level'. Here, examiners, through mitigation strategy, assist writers in claim-making and allow them to create a discursive space "where readers can dispute their interpretations" (Hyland, 2005, p. 179).

Hyland and Hyland (2001) explain that questions are also useful when one wishes to protect oneself or one's reader from the full effects of what might be considered serious allegations, and that interrogatives weaken a definitive reading of a proposition, and because of this, they can, in some cases, be seen as attempts to withhold full commitment from the possible implications of a statement. Petch-Tyson (1998) explains that, through questions, examiner visibility is realized in the reports. Examiners employ questions to start a dialogue with their readers, inviting readers into the text (Falahati, 2006; Hyland, 2002). By inviting engagement, questions emphasize the essentially dialogic nature of discourse (Bakhtin, 1981). That is, through questions, writers project the perceptions, interests, and needs of a potential audience into their unfolding argument.

\subsection{Personal Responsibility}

Apart from the criticism-praise $(\mathrm{CP})$ pairs, hedging devices and questions used in the data, the last major strategy for mitigating critical comments, among other functions, was the use of personal responsibility. Personal responsibility is employed to introduce a speaker's personal opinion and interpretation of some available information, and to diminish the strength propositions (Hyland, 2000; Hyland \& Hyland, 2001). Some samples from the data are provided here:

I cannot identify the study area from the title of the thesis. (HIS 24)

The study relied solely on secondary data from X which I consider as inadequate for MPhil work. (POH 1)

I have difficulty with the organizing principle of the arrangement of studies on $X$ and $Y$. (ENG 23)

I fail to see the validity of the references to tourism attractions to justify the choice of data. (HOT 17)

Extracts 68-71 exemplify the use of personal mentioning as a means of lessening criticisms in the reports. Giannoni (2002) also found the use of personal responsibility as a way of mitigating negative comments in his study. The presence of ' $I$ ' or its equivalent in the data indicates that it is the examiner who feels or sees that way, and that left to other observers, an error or defect may not be registered. The examiner identifies a problem which ought to be addressed but s/he declines to present the defects categorically; instead, it is skirted in a 
personal tone so that the candidate does not feel attacked by the comment. Specifically, in Extract 71, the examiner asserts that $\mathrm{s} / \mathrm{he}$ fails to see the legitimacy of the mentioning of tourism attractions in the justification of the selection of the data. However, the examiner carries that responsibility of the inadequacy, suggesting that, perhaps, there is a justification but s/he cannot comprehend that - this relieves the candidate of the burden of not having attempted to do the best. Hyland (1995) explains that the use of 'I' (in reference to the examiner) suggests that the comment should be considered as an alternative thought but not a definitive assertion of the truth, which signifies a personal opinion that is to be substantiated. The use of the first-person pronoun, according to Petch-Tyson (1998), helps examiners to intrude and make themselves visible in the reports. 'I' which is usually a Senser participating in Mental Process, and can relate to being non-committed to the message (Martin \& White, 2005). Fløttum (2012) notes that the first pronoun, 'I' is a key feature of voice, and the most overt expressions of stance (Gray \& Biber, 2012, p. 22). The pronouns found in the above extracts, using grammatical roles, are a participant in Mental process and they are about the examiner rather than the candidate. As explained by Starfield et al. (2007), the use of these Senser pronouns makes the examiners uncommitted to the comments. In the view of Hyland (2005), this strategy help the writer withhold complete commitment to a proposition, put emphasis on the subjectivity, and present information as an opinion rather than credited fact, which seen as hedging.

\section{Conclusion and Implications}

The study investigated mitigation strategies employed by examiners in examiners' reports on MPhil theses. Examiners mitigated criticisms because, in the view of Hyland and Hyland (2001), first, they would like to represent themselves as readers rather than individuals who are the custodians of all knowledge in the area of investigation; second, examiners tried not to devastate the candidates by criticizing all issues identified in the work; third, there was the need not to appropriate or usurp students' text; next, to save the face or 'public self-image; and last, as a way of maintaining or developing good relationships with the candidates.

The study investigated the strategies that examiners employed to mitigate critical comments in 100 theses examiners' reports written by examiners on MPhil theses purposively sampled, drawing on Hyland's (2000) taxonomy of strategies. The analysis revealed that critical/negative comments made by examiners in TERs were mitigated through, mainly, the praise and criticism pairs and hedging devices. Also, examiners sparingly employed questions and personal responsibility to mitigate critical comments in TERS.

The study has implications for theory and postgraduate pedagogy. First, the findings of the study imply that examiners not only give comments as they deem fit but also maintain interpersonal roles by mitigating such comments that seem critical, using strategies such as praise-criticism pairs, hedges, and personal responsibility. Theoretically, the study confirms the proposition in SFL that language users make systematic choices from the systematic organization of language to realise meaning (Halliday \& Matthiessen, 2004). Second, the study has implications for teachers and students. The findings give insights to teachers and students on how best to situate their coaching and writing skills respectively for the purposes of maintaining social relationships. For teachers, the use of outright negative comments may demoralize the spirit of students and even destroy interpersonal relationships; thus, the use of mitigation strategies in feedback on student writings will help nurture leaners very well. Again, teachers should not devastate the students by criticizing all issues identified in the work, which may cripple future attempts of such a student. Also, teachers should represent themselves as readers rather than individuals who are the custodians of all knowledge in the area of investigation (Hyland \& Hyland, 2001). Thus, in an attempt to critique a work, there is the need to attenuate such comments. On the other hand, there is the need for students to master writing skills (Lynch, 2014; Paltridge \& Starfield, 2007) as the study offers understandings into how best writings can be produced in the academic community (AC) as well as giving insights into the practices and expectations of examiners in grading these. In other words, academic writing is not wholly objective and impersonal but it is evaluative and interactive (Adel, 2006; Osei, 2013, Thompson \& Hunston, 2000). Thompson and Hunston (2000) espouse that academic discourse is characterised by the interpersonal uses of language and how the subjective presence of the writer or speaker intrudes into 
communication to convey an attitude to both those they address and the material they discuss. Consequently, the student as a writer or a speaker must express an attitude towards a viewpoint or feelings about the entities or propositions being written or talked about. However, the expression of the attitude of a speaker or writer should be made with an attempt to protect him/herself from potential rejection from an interlocutor (Boncea, 2014); thus, the need for the employment of these mitigation strategies in the student writings.

The present study was limited to expert writing which is the thesis examiner's reports. It is recommended, first, that other expert writings like research articles, reference reports, and other review genres could be studied for their use of mitigation strategies since these review genres are rich in the use of evaluative language (Gesuato, 2009; Giannoni, 2009; Starfield et al, 2017). Second, it is recommended that further studies should examine novice writings like essays, proposals and term papers to ascertain what the practices are in relation to offering critical comments. Second, since the study was limited to four departments without an attempt to establish any disciplinary variation, future research could adopt a cross-disciplinary approach to ascertain if there are specific disciplinary strategies to be employed by examiners in the writing of their reports. Besides, specific part-genres of the examiners reports, like Literature Review, Introduction, and Results and Discussion could be studied for the use of specific mitigation strategies as there are genre specific requirements for the writing of each part-genre.

\section{References}

Adel, A. (2006). Metadiscourse in L1 and L2 English. Philadelphia: John Benjamins. https://doi.org/10.1075/scl.24

Alcaraz-Ariza, M. (2010). Evaluation in English-medium medical book reviews. International Journal of English Studies, 11, 137-153. https://doi.org/10.6018/ijes/2011/1/137141

Bakhtin, M. M. (1981). The dialogic imagination: Four essays by M. M. Bakhtin. Austin: University of Texas Press.

Boncea, I. (2014). Hedging patterns used as mitigation and politeness strategies. Annals of the University of Craiova. Series: Philology, English, 2, 7- 23.

Brannon, L., \& Knoblauch, C. H. (1982). On students' rights to their own texts: A model of teacher response. College Composition and Communication, 33, 157-166. https://doi.org/10.2307/357623

Brown, P., \& Levinson, S. (1978). Universals in language usage: Politeness phenomena. In E. Goody (Ed.), Questions and politeness: Strategies in social interaction (pp. 56-310). Cambridge: Cambridge University Press.

Edusie, J. S. (2015). Academic writing in Ghana: Hedging among advanced L2 users of English. Unpublished MPhil thesis. Kwame Nkrumah University of Science and Technology, Ghana.

Eggins, S. (2004). An Introduction to Systemic Functional Linguistics ( $2^{\text {nd }}$ ed.). London: Continuum.

Falahati, R. (2006). The use of hedging across different disciplines and rhetorical sections of research articles. Papers from the $22^{\text {nd }}$ Northwest Linguistic Conference.

Fløttum, K. (2012). Variation of stance and voice across cultures. In K. Hyland \& C. Sancho Guinda (Eds.), Stance and voice in written academic genres (pp. 218-231). United Kingdom: Palgrave. https://doi.org/10.1057/9781137030825_14

Gborsong, P. A., Awiah, J. W., \& Appartaim, A. B. (2018). Linguistic forms in teacher feedback comments on students' essays in colleges of education in Ghana. Journal of English Literature and Cultural Studies, $1(1), 59-94$.

Gesuato, S. (2009). Evaluation guidelines: A regulatory genre informing reviewing practices. In M. Gotti (Ed.), Commonality and individuality in academic discourse (pp. 325-348). New York: Peter Lang.

Giannoni, D. S. (2002). Hard words, soft technology. Criticism and endorsement in the software review genre. In M. Gotti, D. Heller \& M. Dossena, (Eds.), Conflict and negotiation in specialized texts (pp. 335-362). Bern: Peter Lang.

Giannoni, D. S. (2009). Negotiating research values across review genres: A case study in Applied Linguistics. 
In K. Hyland \& G. Diani (Eds.), Academic evaluation: Review genres in university settings (pp. 17-33). United Kingdom, UK: Palgrave Macmillan. https://doi.org/10.1057/9780230244290_2

Gillaerts, P., \& Van de Velde, F. (2010). Interactional metadiscourse in research article abstracts. Journal of English for Academic purposes, 9(2), 128-139.

Goffman, E. (1966). Interactional ritual: Essays on face-to-face behaviour. New York: Aldine De Gruyter.

Gray, B., \& Biber, D. (2012). Current conception of stance. In K. Hyland \& C. Sancho Guinda (Eds.), Stance and voice in academic genres (pp. 15--33). New York: Palgrave. https://doi.org/10.1057/9781137030825_2

Halliday, M. A. K. (1978). Language as social semiotic: The social interpretation of language and meaning. Maryland: University Park Press.

Halliday, M. A. K., \& Matthiessen, C. M. I. M. (2004). An introduction to Functional Grammar (3 ${ }^{\text {rd }}$ ed.). London: Arnold.

Holliday, A. (2007). Doing and writing a research. London: Sage. https://doi.org/10.4135/9781446287958

Hyland, F., \& Hyland, K. (2001). Sugaring the pill: Praise and criticism in written feedback. Journal of Second Language Writing, 10, 185-212. https://doi.org/10.1016/S1060-3743(01)00038-8

Hyland, K. (1995). The author in the text: Hedging scientific writing. Hong Kong Papers in Linguistics \& Language Teaching, 18, 33-42.

Hyland, K. (1998). Hedging in scientific research articles. Amsterdam: John Benjamins.

Hyland, K. (2000). Disciplinary discourse: Social interactions in academic writing. London: Longman.

Hyland, K. (2002). Directives: Argument and engagement in academic writing. Applied Linguistics, 23(2), 215-239.

Hyland, K. (2004). Disciplinary interactions: Metadiscourse in second language post-graduate writing. Journal of Second Language Writing, 13(2), 133-151.

Hyland, K. (2005). Stance and engagement: A model of interaction in academic discourse. Discourse Studies, 7(2), 173- 192.

Itakura, H., \& Tsui, A. B. M. (2011). Evaluation in academic discourse: Managing criticism in Japanese and English book reviews. Journal of Pragmatics, 43, 1366-1379. https://doi.org/10.1016/j.pragma.2010.10.023

Jalali, H. (2017). Reflection of stance through it bundles in applied linguistics. Ampersand, 4, 30-39. https://doi.org/10.1016/j.amper.2017.06.001

Knoblauch, C. H., \& Brannon, L. (1984). Rhetorical traditions and the teaching of writing. New Jersey: Boynton.

Kosonen, R. (2014). Evaluation in preliminary examiners'statements. Unpublished MA thesis. University of Helsinki.

Kumar, V., \& Stracke, E. (2011). Examiners' reports on theses: Feedback or assessment. Journal of English for Academic Purposes, 10, 211-222.

Lakoff, G. (1972). Hedges: A study in meaning criterion and logic of fuzzy forms. Journal of Philosophical Logic, 2, 458-508.

Lynch, T. (2014). Writing up your PhD: Qualitative research. English Language Teaching Centre, University of Edinburgh.

Mackiewicz, J. (2007). Compliments and criticisms in book reviews about Business Communication. Journal of Business and Technical Communication, 21, 118-215. https://doi.org/10.1177/1050651906297168

Martin, J. R., \& White, P. R. (2005). The language of evaluation: Appraisal in English. Basingstoke: Palgrave Macmillan. https://doi.org/10.1057/9780230511910

Musa, A. (2014). Hedging in academic writing: A pragmatic analysis of English and Chemistry Masters' theses in a Ghanaian university. English for Specific Purposes World, 42(15), 1-25.

Ngula, R. S. (2017). Epistemic modal verbs in research articles written by Ghanaian and international scholars: A Corpus-based study of three disciplines. Brno Studies in English, 43(2), 5-27. https://doi.org/10.5817/BSE2017-2-1

Obeng, S. G. (1996). The proverb as a mitigating and politeness Strategy in Akan discourse. Anthropological 
Twumasi, R. A.

Linguistics, 38(3), 521-549.

Osei, Y. A. (2013). Metadiscourse use in English Language and Sociology Masters' Theses in a Ghanaian university. Unpublished MPhil thesis. University of Cape Coast, Ghana.

Paltridge, B., \& Starfield, S. (2007). Thesis and dissertation writing in a second language: A handbook for supervisors. London: Routledge. https://doi.org/10.4324/9780203960813

Quirk, R., \& Greenbaum, S. (1973). A university grammar of English. England: Pearson Education Limited.

Razali, R., \& Jupri, R. (2014). Exploring teacher written feedback and student revisions on ESL students' writings. IOSR Journal of Humanities and Social Sciences, 19, 63-70. https://doi.org/10.9790/0837-19556370

Salager-Meyer, F. (2001). From self-highlightedness to self-effacement: A genre-based study of the Socio-Pragmatic Function of Criticism in Medical Discourse. LSP \& Professional Communication, 1(2), 63-84

Starfield, S., Paltridge, B., McMurtrie, R., Holbrook A., Kiley, M., \& Fairbairn, H. (2017). Evaluation and instruction in $\mathrm{PhD}$ examiner reports: How grammatical choices construe examiner roles. Linguistics and Education, 42, 53-64. https://doi.org/10.1016/j.linged.2017.07.008

Thompson, G. (2014). Introducing functional grammar (3rd ed). London: Routledge. https://doi.org/10.4324/9780203785270

Thompson, G., \& Hunston, S. (2000). Evaluation: An introduction. In S. Hunston, \& G. Thompson (Eds.), Evaluation in text: Authorial stance and the construction of discourse (pp. 1-27) Oxford: Oxford University Press. 